\title{
Differential fMRI Activation Patterns to Noxious Heat and Tactile Stimuli in the Primate Spinal Cord
}

\author{
Pai-Feng Yang, ${ }^{1,2}$ Feng Wang, ${ }^{1,2}$ and Li Min Chen ${ }^{1,2}$ \\ ${ }^{1}$ Institute of Imaging Science and ${ }^{2}$ Department of Radiology and Radiological Sciences, Vanderbilt University, Nashville, Tennessee 37232
}

Mesoscale local functional organizations of the primate spinal cord are largely unknown. Using high-resolution fMRI at 9.4 T, we identified distinct interhorn and intersegment fMRI activation patterns to tactile versus nociceptive heat stimulation of digits in lightly anesthetized monkeys. Within a spinal segment, $8 \mathrm{~Hz}$ vibrotactile stimuli elicited predominantly fMRI activations in the middle part of ipsilateral dorsal horn (iDH), along with significantly weaker activations in ipsilateral (iVH) and contralateral (cVH) ventral horns. In contrast, nociceptive heat stimuli evoked widespread strong activations in the superficial part of $\mathrm{iDH}$, as well as in iVH and contralateral dorsal ( $\mathrm{cDH})$ horns. As controls, only weak signal fluctuations were detected in the white matter. The iDH responded most strongly to both tactile and heat stimuli, whereas the $\mathrm{cVH}$ and $\mathrm{cDH}$ responded selectively to tactile versus nociceptive heat, respectively. Across spinal segments, iDH activations were detected in three consecutive segments in both tactile and heat conditions. Heat responses, however, were more extensive along the cord, with strong activations in $\mathrm{iVH}$ and $\mathrm{cDH}$ in two consecutive segments. Subsequent subunit B of cholera toxin tracer histology confirmed that the spinal segments showing fMRI activations indeed received afferent inputs from the stimulated digits. Comparisons of the fMRI signal time courses in early somatosensory area $3 \mathrm{~b}$ and iDH revealed very similar hemodynamic stimulus-response functions. In summary, we identified with fMRI distinct segmental networks for the processing of tactile and nociceptive heat stimuli in the cervical spinal cord of nonhuman primates.

Key words: hand; monkey; MRI; pain; touch

\section{Significance Statement}

This is the first fMRI demonstration of distinct intrasegmental and intersegmental nociceptive heat and touch processing circuits in the spinal cord of nonhuman primates. This study provides novel insights into the local functional organizations of the primate spinal cord for pain and touch, information that will be valuable for designing and optimizing therapeutic interventions for chronic pain management.

\section{Introduction}

The spinal cord serves as the first central station for transmitting and modulating pain signals from the body and controls certain reflexes via local circuits (Chambers et al., 1970; Barnes and Schadt, 1979; Davidoff and Hackman, 1991) and also plays a key role in transitioning acute pain into chronic pain under certain pathological conditions (Woolf and Salter, 2000; Woolf, 2011).

\footnotetext{
Received Feb. 11, 2015; revised May 26, 2015; accepted June 15, 2015.

Author contributions: F.W. and L.M.C. designed research; P.-F.Y., F.W., and L.M.C. performed research; P.-F.Y. analyzed data; P.-F.Y. and L.M.C. wrote the paper.

This work was supported by the National Institutes of Health Grants NS069909 (L.M.C.) and NS078680 (J.C.G.), Vanderbilt Core Grant P30EY008126, and the Dana Foundation (L.M.C.). We thank Choahui Tang and Fuxue Xin for technical assistance, Hui-Xin Qi for advice and assistance on anatomical data collection and analyses, Robert Friedman for comments on this manuscript, and Baxter Rogers for guidance in fMRI analysis.

Correspondence should be addressed to Dr. Li Min Chen, Department of Radiology and Radiological Sciences, Institute of Imaging Science, Vanderbilt University Medical Center, AA 1105 MCN, 116121 st Avenue South, Nashville, TN 37232. E-mail: limin.chen@vanderbilt.edu.

DOI:10.1523/JNEUROSCI.0583-15.2015

Copyright $\odot 2015$ the authors $\quad 0270-6474 / 15 / 3510493-10 \$ 15.00 / 0$
}

The majority of spinal cord studies, however, have focused on the ipsilateral dorsal horn (iDH) of nonprimate species. To date, little is known about whether similar fine scale functional organizations and processes are present in the primate spinal dorsal horn and how spinal horns within and across segments work together to process and modulate painful and tactile information. With the technical advances of noninvasive spinal fMRI, it is now feasible to examine responses of the human spinal cord during the perception and modulation of pain (Brooks et al., 2012; Dobek et al., 2014; for recent reviews, see Stroman et al., 2014; Wheeler-Kingshott et al., 2014). Despite these exciting breakthroughs, our ability to localize with precision fMRI activations to individual horns and to visualize their function connections is still limited by technical challenges such as noise, spatial resolution, and image contrast. In this respect, the nonhuman primate has become a good experimental model for localizing and identifying fine scale spinal functional organization, understanding the underlying neural basis of fMRI signals, and developing cut- 

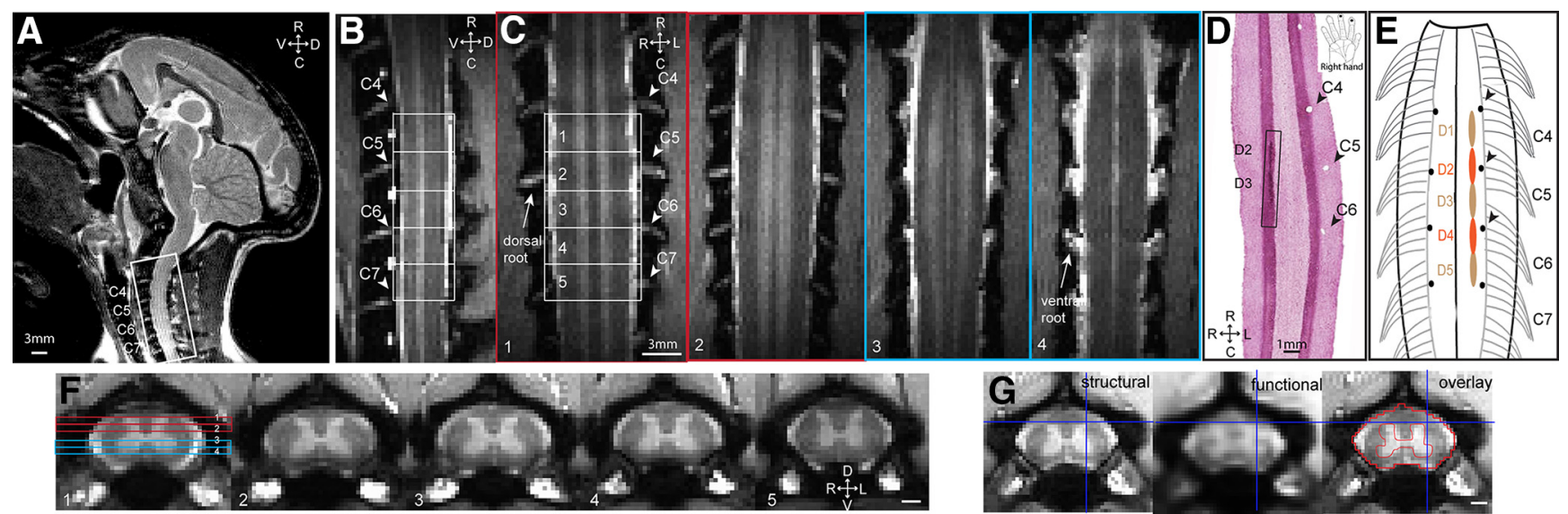

Figure 1. Experimental set up for fMRI of the cervical spinal cord in anesthetized monkeys at 9.4 T. $\boldsymbol{A}$, T2-weighted middle sagittal MRI image (taken from a different imaging session with a volume coil) shows visualization of cervical spinal afferent bundles (white stripes) and the imaging field of view (white outline box) over the cervical spinal cord. D, Dorsal; $V$, ventral; $R$, rostral; $C$, caudal. B, Sagittal view of the spinal cord on a MTC image. Ventral roots are apparent as white bundle strips (labeled as (4-C7). Five white rectangular outlines show the placements of five axial images. C, Four coronal images taken through the dorsal (two red outlined images) and ventral (two light blue outliend images) parts of the spinal cord across both DHs and VHs. Placements of the four coronal images over the DHs and VHs are shown on the first axial image in $F$. GM of spinal horns appeared as two vertical higher intensity white strips on coronal images. The superintense white strips on outer layers of the spinal cord represent space filled with CSF. Cervical dorsal and ventral nerve roots (C4-C7) are visible as horizontal hyperintensity stripes residing between signal void (s) and highlighted by white arrows. D, Aligned coronal section of spinal cord tissue stained with CTB. The rectangular black line box indicates the location of CTB terminal labeling resulting from tracer injections into distal pads of digits 2 and 3 . White pinholes on the opposite side represent landmarks made on the centers of $\mathrm{C} 5-\mathrm{C} 7$ dorsal afferents entry zones on the surface of the spinal cord. $\mathrm{R}$, Right; L, left; R, rostral; $C$, caudal. The schematic hand insert shows the injection sites of (TB tracer on the distal finger pads of digits 2 and 3 of a right hand. $E$, Schematic illustration shows the spatial relationships between the dorsal nerve roots and the digit afferent terminals determined by tracer injections (for original data, see Florence et al., 1991; Qi et al., 2011). Black dots indicate the pinholes locations. $\boldsymbol{F}$, One set of five representative anatomical axial MTC images. Unlabeled scale bars, $1 \mathrm{~mm}$. R, Right; L, left; D, dorsal; V, ventral. Slices 1-5, Rostral to caudal. G, Aligned MTC anatomical (top), fMRI (middle), and the overlap (bottom) images. Red outlines in the overlap image represent the fMRI boundaries of butterfly-shaped GM and spinal cord. Blue lines indicate a corresponding alignment landmark.

ting edge MRI techniques (Fujiyoshi et al., 2007; Lundell et al., 2011).

The nonhuman primate is an invaluable experimental model for examining the neuronal underpinnings of fMRI signals, especially for interpreting human fMRI discoveries. Although this importance has been well demonstrated in monkey fMRI studies on the brain (Logothetis, 2002; Vanduffel et al., 2014), to date, no such comparisons are available for the primate spinal cord. This type of information is hard, if not impossible, to obtain from humans due to apparent ethical and technical reasons, but can be obtained from monkeys with the combination of fMRI, invasive microelectrode recordings, and subsequent histological confirmation. Toward this goal, we have developed high-resolution and high-contrast MRI methods in monkeys. The power and potential of such an approach has been well demonstrated in our recent studies on spinal-cord-injured monkeys (Wang et al., 2014; Chen et al., 2015; Wang et al., 2015).

In the present study, we specifically asked the following questions. (1) Are the fine mesoscale spinal nociceptive fMRI activation patterns observed in monkeys similar to those observed in the human spinal cord at the segmental level? (2) Do nociceptive heat and tactile activation patterns differ? (3) Do fMRI hemodynamic stimulus response functions in the spinal cord differ from that in the brain? We report here that unilateral nociceptive heat and tactile stimulation of digits elicited widespread fMRI activations in bilateral ventral and dorsal horns. Specific within- and across-segmental activation patterns of nociceptive heat and touch differed. This study expands upon early qualitative fMRI results reported in our most recent study (Chen et al., 2015).

\section{Materials and Methods \\ Animal preparation}

Seven adult ( $4-8$ years old) male squirrel monkeys (Saimiri sciureus) were included in this study. During each MRI scan, the monkey was lightly anesthetized with isoflurane $(0.5-1.0 \%$, delivered via a mixture of $\mathrm{N}_{2} \mathrm{O} / \mathrm{O}_{2}, 70: 30$ ) and mechanically ventilated, with head and body stabilized in an MR-compatible frame. No muscle relaxant was used. Vital signals (cardiac and respiratory cycles, end tidal $\mathrm{CO}_{2}$, and pulse oximetry) were monitored and maintained at appropriate ranges throughout the imaging session. Rectal temperature was monitored and maintained between $37.5^{\circ} \mathrm{C}$ and $38.5^{\circ} \mathrm{C}$ by means of a circulating water blanket. All procedures were performed under a protocol approved by the Institutional Animal Care and Use Committee at Vanderbilt University.

\section{In vivo MRI data acquisition}

All MRI scans were performed on an Agilent 9.4 T scanner using a custom-designed saddle-shaped transmit-receive surface coil $(2.5 \times 3$ $\mathrm{cm}^{2}$ in size) positioned over each animal's neck. Extra effort was made to straighten the neck (and the cord) by adjusting the head position to ensure more uniform and reproducible data sampling (Fig. $1 B, C, F$ for representative coronal, sagittal, and axial images). A series of highresolution structural images of the spinal segments that receive afferents from digits were obtained with magnetization transfer contrast (MTC) (TR/TE: 220/3.24 ms) using a Gaussian RF saturation pulse (flip angle: $820^{\circ}$, pulse width: $12 \mathrm{~ms}$, and RF offset: $5000 \mathrm{~Hz}$ ) on all three image plans (axial: $0.25 \times 0.25 \times 3 \mathrm{~mm}^{3}, 128 \times 128$ matrix; coronal: $0.25 \times 0.25 \times$ $0.5 \mathrm{~mm}^{3}$; sagittal: $\left.0.25 \times 0.25 \times 0.75 \mathrm{~mm}^{3}\right)$. T2* weighted functional fast gradient echo (flip angle: $\sim 15^{\circ}$, TR: $24 \mathrm{~ms}$, TE: $6.5 \mathrm{~ms}$, volume acquisition time: $1.54 \mathrm{~s})$ multislice images $\left(0.5 \times 0.5 \times 3 \mathrm{~mm}^{3}, 64 \times 64\right.$ matrix $)$ were acquired with the same slice prescription as the axial MTC images. Within each functional imaging session, typically four to six runs were collected for each stimulus condition (e.g., tactile and/or heat). Each fMRI run (tactile, single, or multitemperature) contained 300-330 image volumes. For noxious heat stimulation runs, $21 \mathrm{~s}$ duration blocks of $47.5^{\circ} \mathrm{C}$ heat were repeated nine times with a $30 \mathrm{~s}$ baseline $\left(32^{\circ} \mathrm{C}\right)$ in between. Noxious heat stimuli were presented on distal finger pads of D2 and D3 and delivered via a thermal probe with rapid heating rate of $70^{\circ} \mathrm{C} / \mathrm{s}$ (Medoc Advanced Medical Systems). Next, $8 \mathrm{~Hz}$ tactile stimuli (in $0.44 \mathrm{~mm}$ vertical indentation) were delivered on the same pair of finger pads via 22 -mm-diameter round probes (driven by an S88 Glass stimu- 
lator; Natus Neurology) and were presented in $30 \mathrm{~s}$ on/off cycles. Probes were in light touch with the skin during the baseline period.

To capture functional responses from the digits, five contiguous axial slices, with the third slice positioned approximately over the C6 spinal segment (that receives afferent input from D3), were acquired in each imaging session. Local fiducial landmarks, including dorsal and ventral nerve roots (which tell us which spinal segments we were sampling from), the cervical enlargement (around C5-C7), and visible alternating gray $(\mathrm{GM})$ and white $(\mathrm{WM})$ matter strips on coronal and sagittal images (Fig. $1 B, D, E$ : the GM appeared to be brighter than the WM), and the butterfly-shaped GM on axial images (Fig. $1 D, E$ ), were used to ensure reproducible placements of image slices across sessions and animals. As shown in Figure 1, the dorsal and ventral roots were best visualized on the series of coronal slices and appeared as high-intensity stripes, whereas the surrounding vertebrae showed as signal voids (black) (Fig. 1C). These visible ventral and dorsal nerve roots permitted accurate estimation of the spinal segments, which later were validated in each animal with subunit B of cholera toxin (CTB) tracer histology (Fig. 1D). In this representative case, CTB tracers were injected into D2 and D3 distal pads (see CTB labels within the black line box in Fig. $1 D$; black arrows indicate the pinholes that were places at the centers of dorsal roots $\mathrm{C} 4-\mathrm{C} 6$ on postmortem tissue). Afferents of D2 and D3 were located rostral and caudal to the center of D5 dorsal root. According to our own observations and previous reports (Florence et al., 1991; Qi et al., 2011), spinal segments $\mathrm{C} 4 / \mathrm{C} 5-\mathrm{C} 7 / \mathrm{C} 8$ receive afferents from all five digits in squirrel monkeys (see schematic illustration in Fig. 1E). Across animals, the specific location of the entering zone of the afferents from each digit varies $\sim 0.5 \mathrm{~mm}$ in the rostral to caudal direction along the cord. More importantly, the high-contrast MTC images allowed accurate selections of ROI voxels within the GM and WM for deriving signal time courses. By applying these optimized fMRI acquisition parameters, a minimally distorted fMRI image [see the well aligned blue lines on the structural (Fig. 1G, left) and functional (Fig. $1 D$, middle)] and very nice alignments of the spinal GM and WM structures could be achieved (Fig. 1D, right).

\section{fMRI data analysis}

Preprocessing. fMRI data went through standard preprocessing steps of slice timing correction and 3D slice motion correction, and then fMRI signals were corrected for physiological noise using RETROICOR (Glover et al., 2000). The functional MR images (upsampled from $0.5 \times$ $0.5 \mathrm{~mm}^{2}$ to $0.25 \times 0.25 \mathrm{~mm}^{2}$ voxel size) were coregistered to MTC images and temporally smoothed with a low-pass filter cutoff frequency of $0.25 \mathrm{~Hz}$. No spatial smoothing was applied. Analysis was performed on all voxels within the spinal cord of each subject using a generalized linear model (GLM), six parameters of motion covariates, and two nuisance parameters, which were derived from a principal components analysis of the time courses of voxels in muscle and CSF, were included in the GLM as nuisance regressors in calculating the GLM fit parameters (i.e., $\beta$-values, AFNI: $3 \mathrm{dDeconvolve).} \mathrm{Under} \mathrm{anesthesia,} \mathrm{motion} \mathrm{was} \mathrm{minimal,}$ with six translation and rotation parameters ranging from $0.02 \pm 0.01$ $\mathrm{mm}(\mathrm{X} ;$ mean $\pm \mathrm{SD}) ; 0.04+0.01 \mathrm{~mm}(\mathrm{Y}) ; 0.01+0.01 \mathrm{~mm}(\mathrm{Z}) ; 0.07+$ $0.02 \mathrm{~mm}$ (Yaw); $0.06+0.04 \mathrm{~mm}$ (Pitch); $0.08+0.06 \mathrm{~mm}$ (Roll) in heat stimulation condition and $0.01+0.01 \mathrm{~mm}(\mathrm{X}) ; 0.03+0.01 \mathrm{~mm}(\mathrm{Y}) ; 0.01$ $+0.01 \mathrm{~mm}(\mathrm{Z}) ; 0.08+0.02 \mathrm{~mm}$ (Yaw); $0.07+0.05 \mathrm{~mm}$ (Pith); $0.06+$ $0.06 \mathrm{~mm}$ (Roll) in tactile stimulation condition. For fMRI analysis, spinal cord masks, excluding voxels outside of the CSF, were applied. Multiple imaging runs (300-340 volumes for each run) obtained within each session were analyzed at both the single- and multiple-run levels. For each run, voxels showing stimulus-related fMRI signal changes at a statistically significantly level of $p \leq 0.05$ threshold (with false discovery rate corrected) and clustering of a minimum of two continuous voxels were defined as activated voxels. Activation maps were displayed as statistical $t$-value maps ( $t$-value $2.77=p$ value of 0.05 and $q$ value of 0.03 based on our fMRI experimental design). Group analyses were also performed using a fixed-effects model by taking $\beta$-values to contrast the responses across runs within each animal (AFNI: $3 \mathrm{dttest}++$ ).

Generation of activation frequency map. To evaluate the across-run and across-subject reproducibility of fMRI activation maps to tactile or noxious heat stimulation, we generated frequency maps after manually align- ing axial imaging slices according to the white and GM landmarks and their corresponding spinal segment levels. For example, in the case shown in Figure $1, B$ and $C$, axial slice 2 corresponded to the cervical spinal segment of C6. Based on aligned activation maps, a convergence map was generated to indicate the frequency of activation (color-coded) observed in the dorsal horns across runs within each imaging session or across subjects. The frequency map was overlaid on anatomical MTC images for display (for examples, see Fig. 3).

ROI based time course analysis. An ROI-based time course analysis was used to first quantify fMRI response strengths in different spinal GM regions at the single animal level and then compared at the group level. ROIs within the ipsilateral and contralateral DHs and VHs and WM (two to three regions) were manually selected on a slice-by-slice basis according to the aligned MTC axial images. The time course of fMRI signal change was extracted from up to 3 voxels with highest $t$-values within each ROI and averaged across all stimulus blocks and runs from each imaging session. The mean time courses were then averaged for tactile and heat stimulation conditions at the group level. A nonparametric Kruskal-Wallis one-way ANOVA analysis followed by the Dunn's method for multiple comparisons was used to determine the statistical significance of the response magnitude. $p \leq 0.05$ was considered statistically significant. The analysis results were presented as mean \pm SE in graphs (see Figs. 4, 6).

\section{Tracer histology}

To confirm the localization of the stimulus-evoked fMRI activation along the cord; we used the anatomical tracer CTB (Sigma-Aldrich) to identify the spinal segments that receive sensory afferents from the digits where external stimulation was applied; $10-20 \mu \mathrm{l}$ of $1 \%$ CTB was injected subcutaneously into digits of one or both hands 1 week before the terminal experiment. Postmortem spinal cord tissue was removed after perfusion. All staining procedures followed previously published methods (Florence et al., 1991). For coregistration between coronal MRI images and histological tissue sections, small metal pins were inserted into the middle of dorsal root afferent entrance zones to produce anatomical landmarks for individual spinal segment (for one example, see Fig. 1). Three important steps are taken to make the histological confirmation as accurate as possible. First, in each animal, we injected CTB tracers into the skin of the digits stimulated (e.g., D2 and D3 distal finger pads in Fig. $1 C)$ to help localize the spinal segment showing fMRI activations. Second, we carefully identified both the ventral and dorsal cervical nerve bundles (C1-C8) postmortem. Before removing the spinal cord from the body, we placed needles into the middle of each dorsal root entering zoon (C4-C7) to produce alignment landmarks with the CTB label (see Fig. $1 C, D)$. Last, we used the overall shape and counted nerve bundles to coregister MRI images with CTB histology with dorsal nerve root pinhole landmarks. These procedures ensured a good alignment between MRI and histology images.

\section{Results}

Distinct fMRI activation patterns to nociceptive heat versus innocuous tactile stimulation of digits within and across spinal segments

We first mapped nociceptive heat and tactile stimuli-evoked fMRI activations within the GM of the cervical spinal cord. Figure 2 shows representative data from three monkeys. In response to 8 $\mathrm{Hz}$ vibrotactile stimulation of the distal finger pads of digits 2 and 3 (D2 + D3) of the right hand of two monkeys (SM-B and SM$\mathrm{K})$, fMRI activation clusters were primarily detected in slice 2 with strong activation foci (orange patches with high $t$ values) in the middle layers of the iDH (Fig. $2 A, B$ ). Slices 2 and 3 corresponded to the somatotopically appropriate cervical spinal segments of C5 and C6 that receive afferent inputs from D2 and D3, as later confirmed with CTB tracing histology (Fig. 1D). Similarly, tactile stimulation of the left hand of SM-B evoked strong fMRI activations in the iDH (left) of slice 2, along with activations on other slices (Fig. 2C). Interestingly, in some of the slices, ad- 

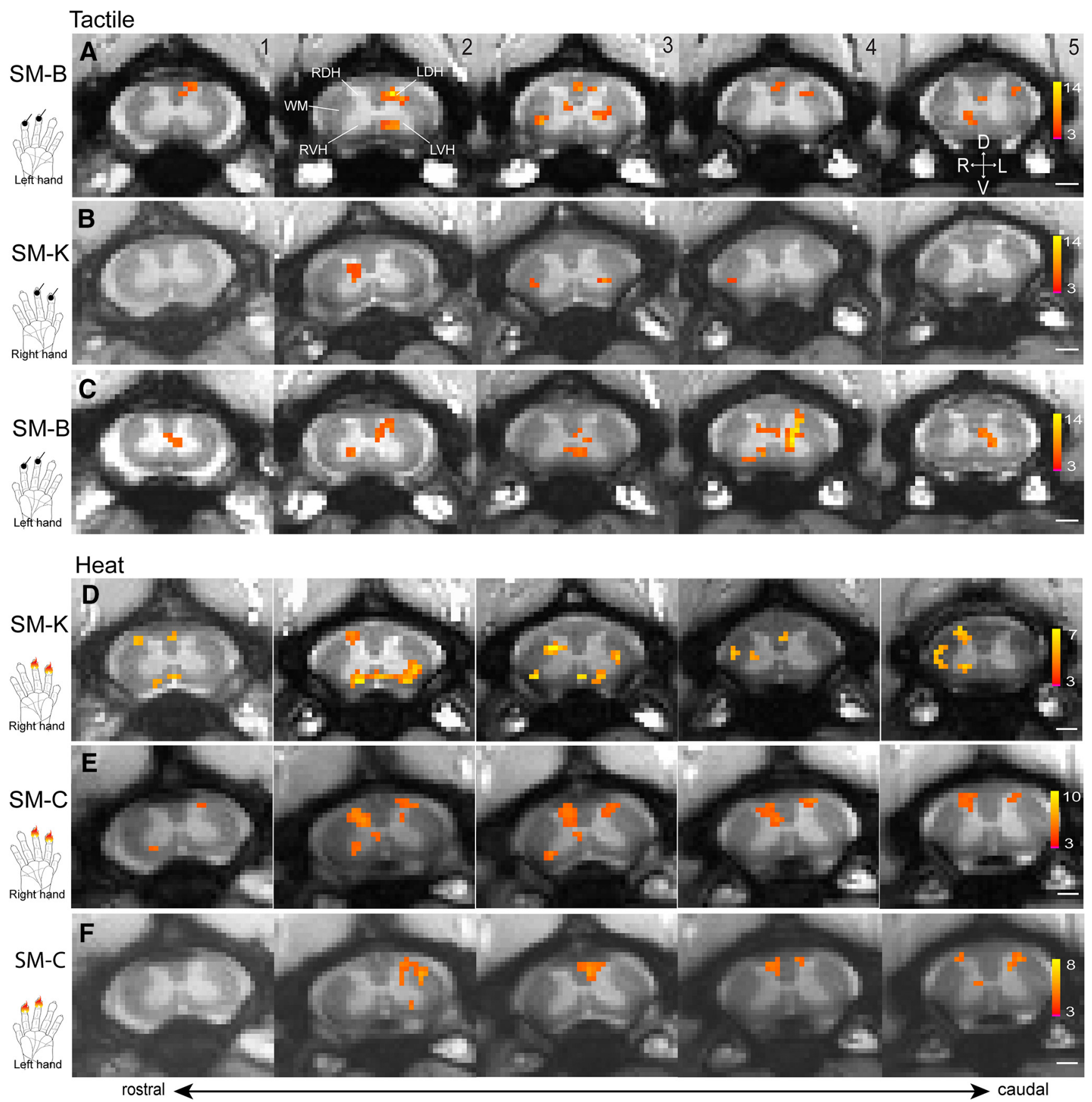

Figure 2. Representative $\mathrm{fMRl}$ activations to tactile and nociceptive heat stimulation of two distal finger pads in three monkeys (SM-K, SM-C, and SM-B). $A$, Single-run fMRI activations to tactile stimulation of two distal finger pads on right hands. $\boldsymbol{B}, \boldsymbol{C}$, Multirun average $\mathrm{MMRl}$ activations to tactile stimulation of two distal finger pads on right $(\boldsymbol{B})$ and left $(\boldsymbol{C})$ hands. $\boldsymbol{D}-\boldsymbol{F}$, Multirun average fMRI activations to $47.5^{\circ} \mathrm{C}$ nociceptive heat stimulation of two distal finger pads on right $(\boldsymbol{D}, \boldsymbol{E})$ and left $(\boldsymbol{F})$ hands. Hand inserts show the locations of stimulation. All activation maps are thresholded at $p<0.05$ for multirun and $p<0.01$ for single run with FDR corrected; see color scale bar on image 5 for the $t$ value range. Images $1-5$, From caudal to rostral. Scale bars, $1 \mathrm{~mm}$. D, Dorsal; $V$, ventral; $L$, left; $R$, right.

ditional fMRI activation foci were observed in both the ipsilateral VH (iVH) and contralateral VH (cVH) (Fig. 2A2) and the neck region between the $\mathrm{DH}$ and $\mathrm{VH}$ (Fig. 2A3). Compared with the tactile activation pattern, nociceptive heat stimulation of the same finger pads of either the right or left hand elicited wider spread activations (Fig. $2 D-F$ ). Across all five slices, the strongest activation foci were detected predominantly in slices 2 and 3 , even though activations in other slices were also present. Within each slice, the centers of heat activation were located more dorsally toward the edges of the $\mathrm{DH}$, corresponding to more super- ficial layers (cf. Fig. 2C2, E2). In addition, nociceptive heat stimulation elicited fMRI activations in bilateral DHs (slices 2 and 3 in Fig. 2E) and bilateral VHs (slices 2-4 in Fig. 2E). Notably, in some cases, activations were detected in WM regions, but the specific locations varied (Fig. 2A5,D5).

Reproducibility of layer-preferential tactile and heat activations in the iDH

Different parts (layers) of the iDH are known to process peripheral tactile and nociceptive heat inputs. Therefore, using this 


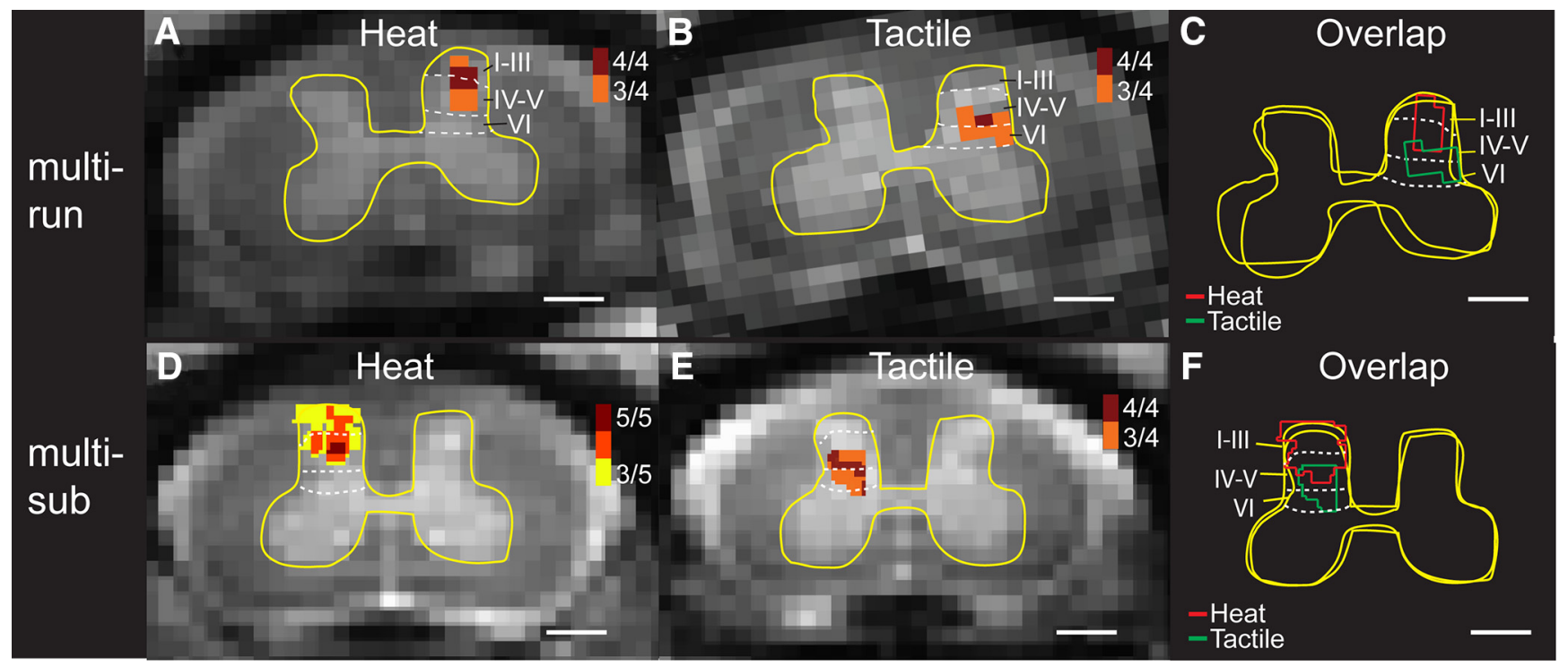

Figure 3. Comparison of locations of fMRI responses to tactile versus nociceptive heat stimuli in the iDH. $A$, Cross-run (multirun) probability map of $47.5^{\circ} \mathrm{C}$ nociceptive heat-evoked activations in the iDH to stimulation of digits 2 and 3 on the left in one representative monkey. 4/4, Four of four runs. $B$, Corresponding cross-run probability map of tactile stimulation evoked activations in the same monkey. C, Overlay map of the cross-run heat and tactile activations. D, Cross-subjects (multisub) probability map of heat activations in the iDH. 5/5, Five of five subjects. $\boldsymbol{E}$, Corresponding cross-subject probability map of tactile activations. $\boldsymbol{F}$, Overlay map of the cross-subject heat and tactile activations. Red and green lines indicate the outlines of heat and tactile activation clusters, respectively. Yellow outlines represent the outer boundaries of the GM. Dotted white lines indicate the approximate borders of interlaminar segments within the DH. Scale bars, $1 \mathrm{~mm}$.
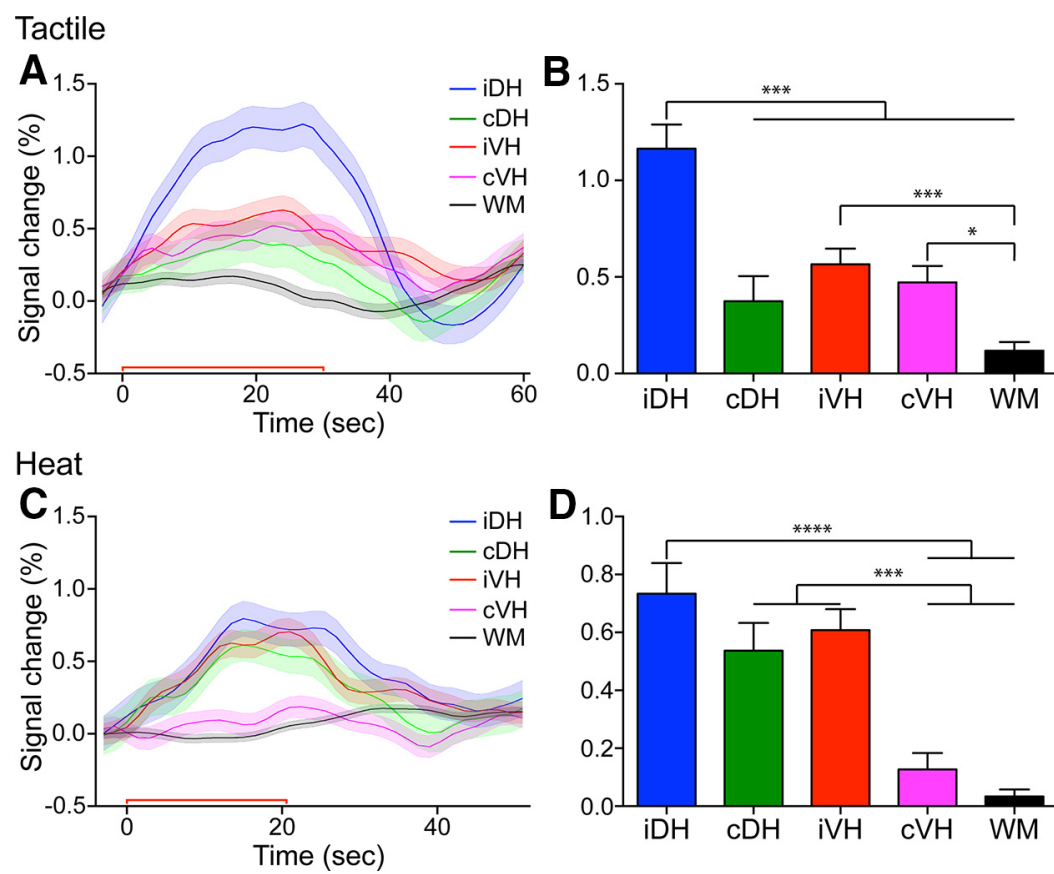

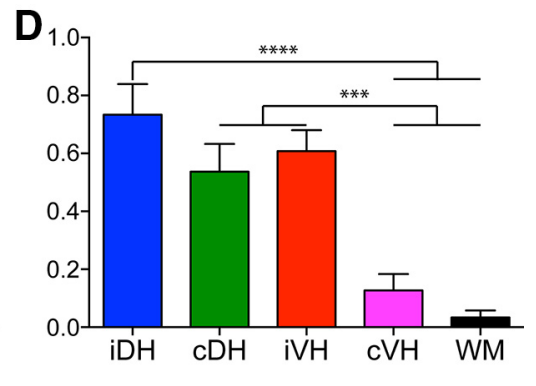

Figure 4. Group comparisons of $\mathrm{fMRI}$ response magnitudes in different parts of the spinal matter within a single spinal segment. $\boldsymbol{A}, \boldsymbol{C}$, Time courses of fMRI signal changes to unilateral tactile $(\boldsymbol{A})$ and nociceptive heat $(\boldsymbol{C})$ stimulation of two distal finger pads in the $\mathrm{iDH}, \mathrm{CDH}, \mathrm{iVH}$, and $\mathrm{CVH}$ and one WM control region. Color lines and shadows indicate mean $\pm \mathrm{SE}$ of the percentage fMRI signal changes. The red lines near the $x$-axis show the stimulation periods of $30 \mathrm{~s}$ for tactile and $22 \mathrm{~s}$ for heat, respectively. $\boldsymbol{B}, \boldsymbol{D}$, Statistical comparisons of the peak magnitudes of fMRI signal changes during tactile $(\boldsymbol{B})$ and nociceptive heat $(\boldsymbol{D})$ stimulation across different intraslice horn and WM regions. Each bar represents the percentage of fMRI signal changes as mean $\pm \mathrm{SE}$. ${ }^{*} p<$ 0.05 ; ${ }^{* * *} p<0.005$; ${ }^{* * *} p<0.001$.

known structure as an experimental model, we further evaluated the reproducibility of spinal activations and the differentiability in separating the foci of touch versus nociceptive heat activation. Figure 3 illustrates the probability (frequency) maps for different runs (across-run) within a single imaging session (Fig. $3 A$ ) and for different subjects (across-subject) (Fig. 3B). Using laminar parcellation lines as a reference, it was clear that the heat activation foci were located at the more superficial part (layer I-III) of the DH (Fig. $3 A, D$ ), with the dark red voxels representing the most reproducible activation focus. In contrast, tactile activation foci were located in more middle part of the $\mathrm{DH}$ (Fig. $3 B, E$ ). The composite maps (Fig. $3 C$ for across-run and Fig. $3 F$ for across-subject) showed the separation of heat (red outlines) and tactile (green outlines) activations and their dorsal to ventral organization. These data indicate that fMRI activations detected in the spinal cord are reproducible and that fMRI is capable of separating spatially nociceptive heat and tactile activation.

\section{Differential cross-horn fMRI response magnitudes to tactile versus nociceptive heat stimuli within a single spinal segment}

We next investigated whether the DHs and $\mathrm{VHs}$ responded differently to tactile versus nociceptive heat stimuli by comparing peak magnitudes (Fig. $4 B, D$ ) calculated from group-averaged fMRI signal time courses (Fig. $4 A, C$ ) that were extracted from slices 2 and 3. Direct comparisons of the response magnitudes derived from the iDH, contralateral $\mathrm{DH}$ $(\mathrm{cDH}), \mathrm{iVH}$, and $\mathrm{cVH}$ and control WM voxels revealed several features. First, in both tactile and nociceptive conditions, the iDH always responded with the strongest magnitudes to the unilateral stimulations (blue lines and columns in Fig. 4). As controls, WM regions only exhibited negotiable signal fluctuations (black lines and columns in Fig. 4). 

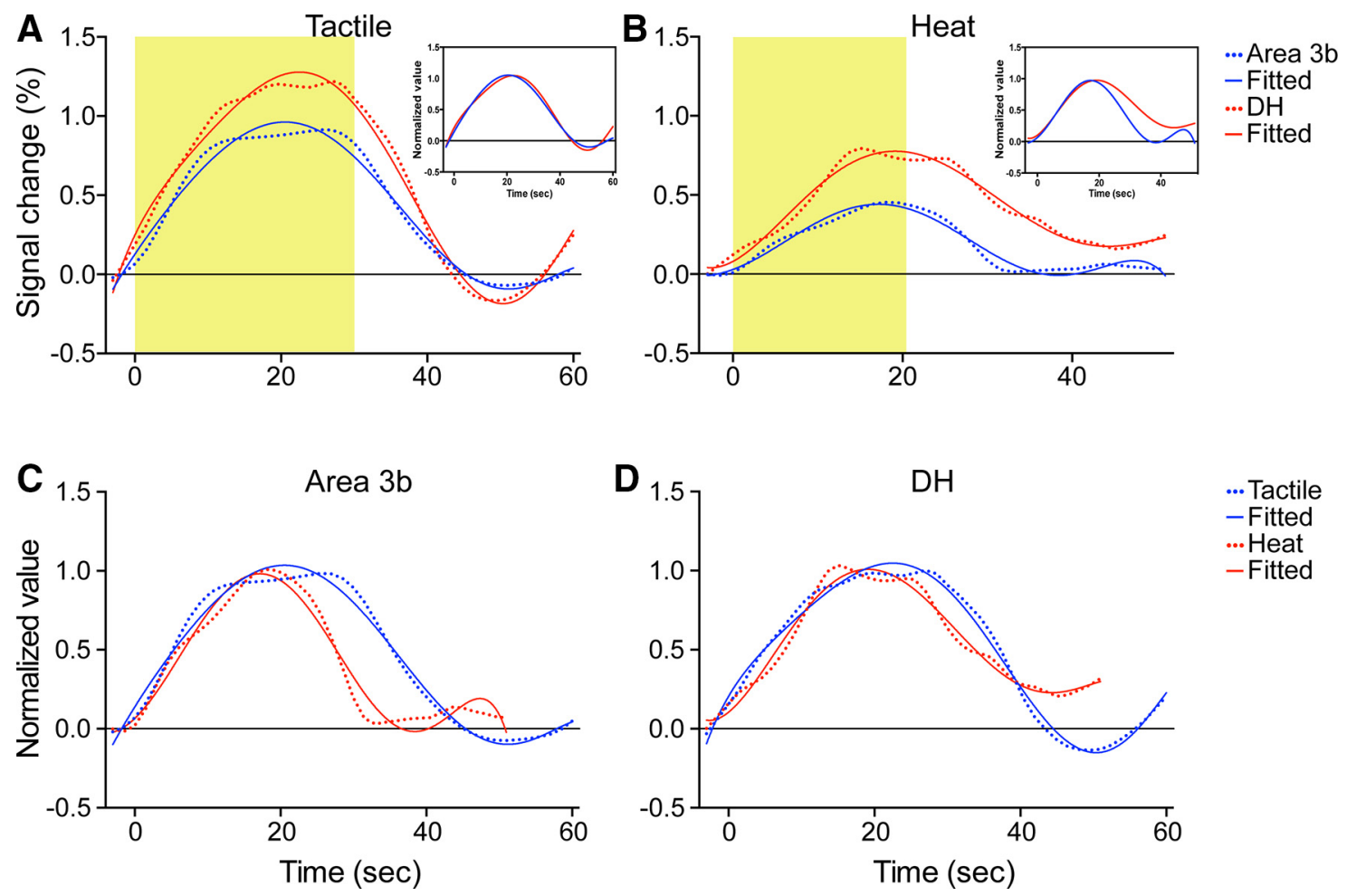

Figure 5. Comparisons of the HRFs between the spinal DH and somatosensory area $3 \mathrm{~b}(\boldsymbol{A}, \boldsymbol{B})$ and heat and tactile $(\boldsymbol{C}, \boldsymbol{D})$ stimulation. $\boldsymbol{A}, \boldsymbol{B}$, Mean fMRI time courses (dotted color lines) and the corresponding two gamma fitting curves (solid color lines) in tactile $(\boldsymbol{A})$ versus nociceptive heat $(\boldsymbol{B})$ stimulation conditions. Yellow shadows indicate the durations of stimulation. $\boldsymbol{C}, \boldsymbol{D}$, Normalized and fitted fMRI time courses to tactile (blue lines) versus heat (red lines) stimulation in area $3 \mathrm{~b}(\boldsymbol{C})$ and $\mathbf{D H}(\boldsymbol{D})$. Note that the durations for heat and tactile stimuli are different. Area $3 \mathrm{~b}$ fMRI time courses reported previously (Chen et al., 2007) were used in this comparison.

Second, the $\mathrm{cDH}, \mathrm{cVH}$, and $\mathrm{iVH}$ responded differently to heat versus the tactile stimulus condition. For example, to touch stimulation, the signal amplitude of $\mathrm{iDH}(1.17 \pm 0.12 \%$, mean \pm SE) was approximately two times as large as those of $\mathrm{cDH}(0.37 \pm 0.13)$, iVH $(0.57 \pm 0.08 \%)$, and $\mathrm{cVH}(0.47 \pm$ $0.08 \%$ ) horns (cf. blue with red, green, and magenta lines in Fig. $4 A, B)$. The response magnitude differences across the four horns were most apparent in Figure $4 B$. The magnitude of signal in WM was $0.12 \pm 0.05 \%$.

Although the signal magnitude of $\mathrm{iDH}$ was the largest $(0.73 \pm 0.11 \%)$ with nociceptive heat stimulation (Fig. $4 C, D)$, the iVH and $\mathrm{cDH}$ also responded robustly with comparable magnitudes (iVH: $0.61 \pm 0.07 \%$; cDH: $0.54 \pm 0.10 \%$ ). There were no significant differences between the response magnitudes of these three horns (cf. blue, green, and red columns in Fig. $3 D)$. Interestingly, the signal in $\mathrm{cVH}(0.13 \pm 0.05 \%)$ was weak and did not differ from that of WM $(0.03 \pm 0.02 \%$, cf. magenta with black columns in Fig. 4D).

To summarize, unilateral tactile stimuli evoked a robust response in iDH, but significantly weaker signal changes in the iVH and $\mathrm{cVH}$. Nociceptive heat stimuli, however, elicited equally strong fMRI responses in the $\mathrm{iDH}, \mathrm{iVH}$, and $\mathrm{cDH}$. The $\mathrm{cDH}$ and $\mathrm{cVH}$ were the most selective in responding only to nociceptive heat or tactile stimuli, respectively (for schematic illustration, see Fig. 7).

Comparison of the hemodynamic response functions of fMRI signals in spinal GM and somatosensory area $3 \mathrm{~b}$

To determine whether the spinal GM exhibits a similar hemodynamic response function (HRF) to brain GM, we compared the
fMRI signal time courses obtained from the spinal DH and somatosensory area $3 \mathrm{~b}$ in both nociceptive heat and tactile stimuli conditions (Fig. 5). We first fitted the raw signal time courses (dotted lines in Fig. $5 A, B$ ) with a two-gamma model (solid lines in Fig. $5 A, B$ ) and found that the fMRI signals at the DH matched very well with the two-gamma function. Direct correlation analysis of the two time courses from the iDH and area $3 \mathrm{~b}$ yielded a high correlation coefficient of 0.98 ( $r$ value) in tactile stimulation conditions (Fig. 5A) and 0.89 in heat stimulation conditions (Fig. $5 B$ ), indicating a high level of similarity of these two HRF curves. Normalized amplitude plots of area $3 \mathrm{~b}$ and DH signals (Fig. $5 A, B$, inserts) revealed their similar HRF shapes, but different HRF duration. Furthermore, compared with area $3 b$, the responses of the iDH were stronger and lasted longer, particularly in the nociceptive heat stimulation condition (Fig. $5 A, B$ ). Last, in both regions, touch signals occurred a bit earlier (not significantly) than heat signals (cf. blue with red curves in Fig. 5C,D). The specific parameters of time-to-peak and peak magnitudes derived from the two-gamma fitting were summarized in the Table 1. One final note is that differences in stimulus durations likely contributed to the differences in durations of HRFs.

Group comparison of tactile versus nociceptive heat-evoked fMRI responses across spinal segments along the spinal cord Each spinal segment receives spatially specific inputs originating from different parts of the body. We therefore investigated whether spinal cord fMRI activations to digital stimulation were spatially constrained to somatotopically appropriate spinal segments and whether the intraslice activation patterns varied across segments along the cord. Tactile stimulation of digits D2 and D3 
Table 1. Two gamma fitting parameters

\begin{tabular}{llllll}
\hline Area & Peak (\%) & TTP $(s)$ & UShot (\%) & $R$ & FWHM (s) \\
\hline Tactile & & & & & \\
$\quad$ Area 3b & 0.93 & 20.6 & -0.07 & 0.99 & 30.32 \\
$\quad$ DH & 1.22 & 23.4 & -1.67 & 0.99 & 32.31 \\
Heat & & & & & \\
$\quad$ Area 3b & 0.45 & 15.1 & & 0.87 & 21.64 \\
$\quad$ DH & 0.77 & 17.3 & & 0.93 & 24.39 \\
\hline
\end{tabular}

TTP, Time-to-peak; Ushot, under shot; FWHM, full-width at half-maximum.

elicited robust fMRI signal changes in the iDHs of three neighboring slices (iDH: $0.96 \pm 0.16 \%$; Fig. $6 \mathrm{~A}$, blue columns in Fig. $6 B)$ and $\mathrm{iVH}(0.79 \pm 0.14 \%$, green columns in Fig. $6 A)$ of one slice (slice 3 in Fig. $6 B$, red column). Heat stimulation of the same set of digits, however, not only evoked robust fMRI signal changes in iDH of three neighboring slices (slices 1-3), but also strong responses in $\mathrm{CDH}(0.50 \pm 0.13 \%)$ and $\mathrm{iVH}(0.53 \pm 0.09 \%)$ in two image slices (slices 2 and 3, Fig. 6D). Across horns and segments (slices), only cDH $(0.35 \pm 0.15 \%$ vs $0.59 \pm 0.14 \%$; cf. red column groups in Fig. $6 A, C$ ) showed differential response patterns to tactile versus heat stimuli. These quantifications indicate that heat stimuli elicited more widespread responses across horns and spinal segments.

\section{Histological postmortem validation of the spinal segments}

We performed CTB tracer histology to validate the spinal cord segments where fMRI activations were detected. On the histological CTB-stained coronal slice, dense CTB terminals resulting from D2 and D3 injections were clustered together as a 6-mmlong strip (emphasized by the rectangular black box in Fig. 1C). For each digit, the afferent entrance zone spread $\sim 3 \mathrm{~mm}$ in the rostral to caudal direction along the cord. A 3-mm-thick MRI axial slice approximately samples fMRI activity from a single spinal segment. Therefore, fMRI activations detected in slices 2-3 correspond to somatotopically appropriate C5-C6 spinal segments.

\section{Schematic summary of the differential fMRI activation patterns to tactile versus nociceptive heat stimulation within and across spinal segments}

Figure 7 summarizes the main findings observed in the present study. Simultaneous tactile (Fig. 7A) versus heat (Fig. 7B) stimulation of two digits evoked distinct activation patterns with differential spinal cord response profiles. Tactile stimuli activate predominantly the iDHs of the stimulated spinal segments. Noxious heat stimulation of the same pair of digits, however, evokes additional strong activations in the $\mathrm{iVH}$ and $\mathrm{cDH}$ in three adjacent segments. The different functional organization of the heat response in a more superficial region and tactile activation in a more middle location in the $\mathrm{DH}$ are also indicated by the locations of the circular cones. Together, our data illustrate different local segmental circuitries for the processing of innocuous tactile and noxious heat inputs.

\section{Discussion}

\section{Differential segmental functional circuitries for nociceptive} heat versus tactile inputs

Pain- and touch-related fMRI activations detected in human spinal cord are characterized by somatotopical organization and predominantly ipsilateral responses (Willis and Coggeshall, 2004b; Nash et al., 2013; Summers et al., 2013), with some reports of bilateral activations (Ghazni et al., 2010; Summers et al., 2010; Brooks et al., 2012; Summers et al., 2013; Wheeler-Kingshott et al., 2014). With the assistance of enhanced signal- and contrastnoise ratios at ultra-high MRI field $(9.4 \mathrm{~T})$, the present study extended the observations in humans and refined the within and across segmental functional circuitries for the processing of nociceptive and tactile inputs in monkeys. Three main features characterize the local networks for touch and nociceptive heat processing. First, the iDH is the primary processing station for nociceptive heat and tactile inputs and each is preferentially processed in different (superficial vs deep) layers. The finding of layer-specific processing of noxious heat versus tactile inputs are consistent with the exvivo (for reviews, see Petkó and Antal, 2012; Abraira and Ginty, 2013) and in vivo observations in other animals (primarily rodents) (Cook et al., 1987; Furue et al., 2004; Stanfa and Dickenson, 2004). The spatial agreement between the layer preferential fMRI activation and electrophysiological recordings indicate that fMRI signals detected in the spinal cord GM indeed reflect the underlying neuronal electrophysiological activity. Second, within a single spinal segment, the cross-horn activation pattern on the contralateral side ( $\mathrm{cVH}$ vs $\mathrm{cDH})$ differentiates the nociceptive versus touch network. Although the ipsilateral horns are responsive to both nociceptive heat and tactile stimuli, the $\mathrm{cDH}$ responds more selectively to nociceptive heat than tactile stimuli. Inversely, the $\mathrm{cVH}$ responds more selectively to tactile than nociceptive heat stimuli. In contrast, the iDH and iVH are both strongly engaged in nociceptive heat and tactile processing. Third, tactile and nociceptive heat inputs engaged multiple somatotopically appropriate spinal segments, but to a different spatial extent. Along the cord, the tactile circuitry is spatially constrained to the $\mathrm{iDH}$.

Several mechanisms likely contribute to the widespread and differential heat and touch fMRI activations. For example, the VH activation to unilateral painful stimuli may be explained by the engagement of local spinal reflex circuitry. Indeed, pain-related fMRI signals appeared to be also present at the VH of human spinal cord (Cahill and Stroman, 2011; Stroman et al., 2012; Dobek et al., 2014). However, the observation of similar responses to innocuous tactile stimuli suggests that the VH likely plays more roles than just mediating simple pain-signal related reflex activity. Bilateral engagement of VHs may be associated with coordinated bilateral locomotor functions of the forelimbs of new world monkeys. There is evidence suggesting that the processing of painful stimuli engages complex spinal segmental circuitries (Stroman et al., 2012).

The signature $\mathrm{cDH}$ activation to nociceptive stimulation may be a result of top-down descending modulation (Willis and Coggeshall, 2004a; Abraira and Ginty, 2013) or interactions via commissural connections between DHs (Cook et al., 1984; Koltzenburg et al., 1999; Petkó and Antal, 2012). Indeed, several studies in humans have demonstrated profound modulation of activation in the DHs of the spinal cord in placebo analgesia (Eippert et al., 2009), nocebo hyperalgesia (Geuter and Büchel, 2013) and cognitive distraction (Sprenger et al., 2012). Because prolonged nociceptive stimuli were used in our study, feedback influences are likely imbedded in the detected fMRI signals. Our demonstration of bilateral $\mathrm{DH}$ and $\mathrm{VH}$ activations to unilateral noxious and tactile stimuli in anesthetized monkeys speaks strongly for the fundamental importance of the circuitry among the horns within and across segments.

\section{Functional importance of the local spinal circuitry}

From a systems neuroscience perspective, the identification of differential segmental processing circuitries for tactile versus nociceptive heat stimuli has several functional and clinical implications. For example, simultaneously engaged and highly con- 

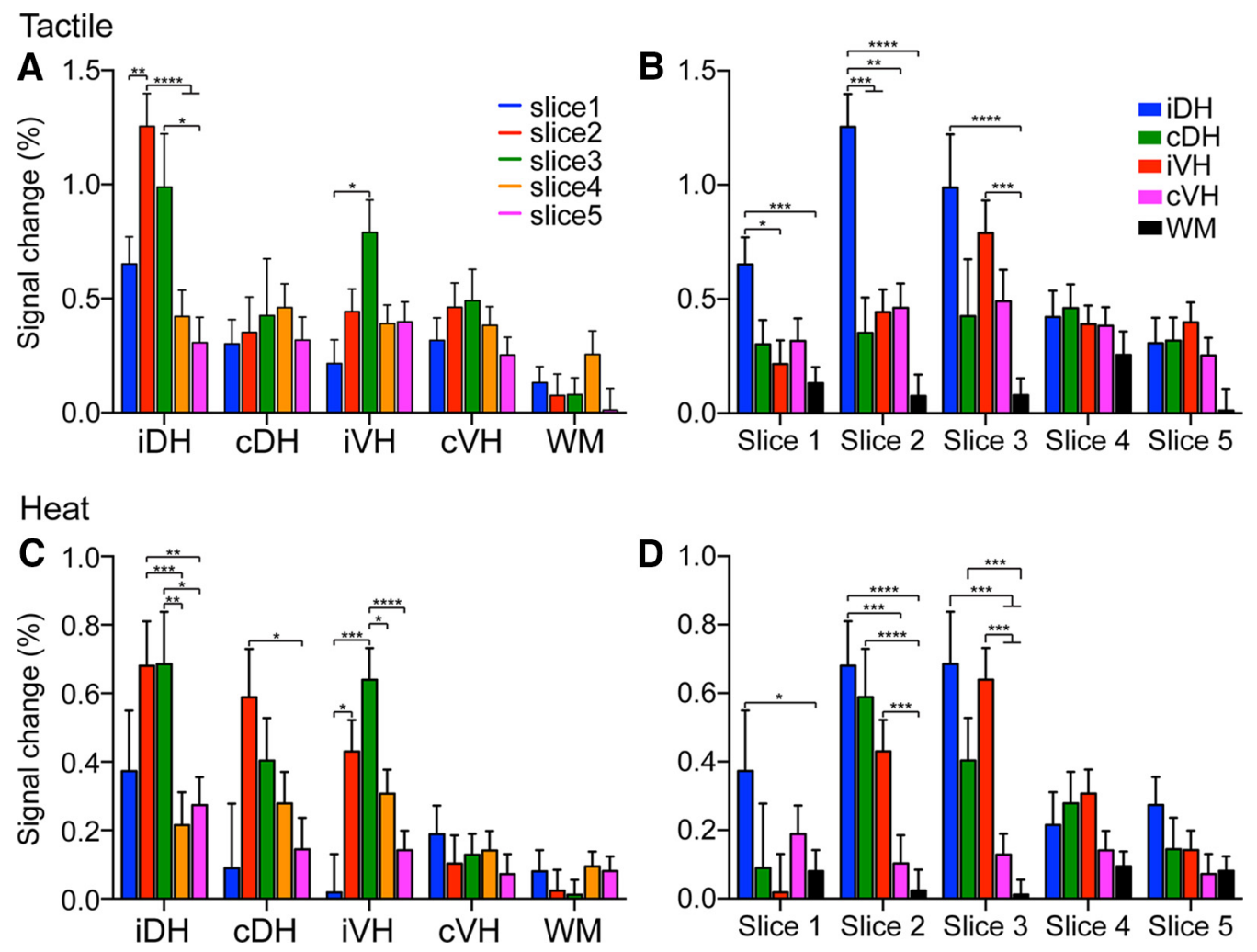

Figure 6. Spatial distributions of the magnitudes of fMRI responses to tactile versus heat stimuli in different horns and the control WM across spinal segments (image slices) along the cord. $A, C$, Distributions of $f M R I$ responses magnitudes across image slices $1-5$ during tactile $(\boldsymbol{A})$ versus nociceptive heat $(\boldsymbol{C}$ stimulation in different ROls (four horns and one WM). $\boldsymbol{B}, \boldsymbol{D}, \mathrm{Magnitudes}$ of the fMRI responses across different ROls (four horns and one WM) as a function of image slices 1-5 during tactile $(\boldsymbol{B})$ versus nociceptive heat $(\boldsymbol{D})$ stimulation. Signal magnitude is presented as mean percentage signal change + SE. ${ }^{*} p<0.05 ;{ }^{* *} p<0.01 ;{ }^{* * *} p<0.005 ;{ }^{* * * *} p<0.001$. Slices $1-5$, Caudal to rostral.

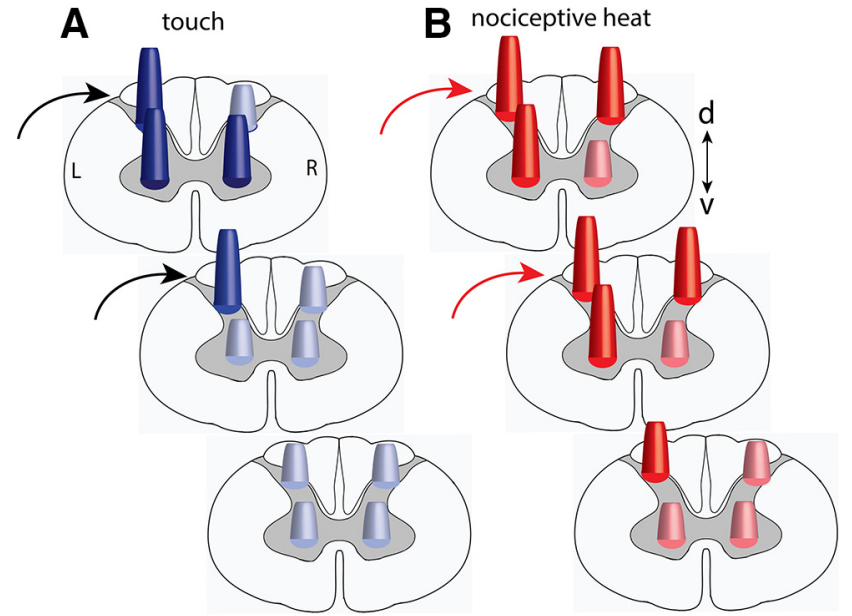

Figure 7. Schematic summary of the differential activation patterns to tactile $(\boldsymbol{A})$ versus nociceptive heat $(\boldsymbol{B})$ stimulation within and across spinal segments. Dark color cones indicate responses are statistically significant.

nected DHs may explain the bilateral and diffused hyperalgesia and allodynia symptoms that are commonly reported in chronic low back pain conditions, even though only unilateral injury or pathological changes were identifiable (Koltzenburg et al., 1999; Huang and $\mathrm{Yu}, 2010$ ), or in animal pain models when only unilateral injury is introduced (Kim and Chung, 1992; Chen et al., 2000)

It is likely that coordinated activities between DHs and VHs on one side or between horns on both sides are fundamental in mediating sensory perception and subsequent behavioral re- sponses. Recent identifications of local intrinsic horn-horn functional connections in normal human spinal cord support this notion (Barry et al., 2014; Kong et al., 2014). Furthermore, our recent demonstrations of the injury-induced alterations in horn-horn functional connectivity underscored the functional and behavioral relevance of the local spinal horn-horn networks (within and across spinal segments; Chen et al., 2015). From the clinical point of view, these observations indicate that it may be necessary to consider targeting both $\mathrm{VH}$ s and $\mathrm{DH}$ in multiple segments when designing or refining effective electrical spinal stimulation paradigms for chronic pain treatment and restoring motor function.

\section{HRFs and fMRI activation detection in spinal GM}

Vascular structures of the brain and spinal cord differed substantially. Therefore, an accurate estimation of the HRF of fMRI signals is important for generating a mathematical model for detecting and quantifying external stimulus-associated fMRI signal changes in spinal cord. To date, however, only fMRI HRF in the brain was fairly well characterized (Woolrich et al., 2004; Arichi et al., 2012; Marxen et al., 2012). Little is known about whether the spinal GM exhibits a similar HRF (Brieu et al., 2010; Summers et al., 2010). Direct comparisons between the fMRI signal changes obtained in the spinal cord and somatosensory area $3 \mathrm{~b}$ to identical stimulation showed that the HRFs in these two regions are quite comparable. Therefore, the classical HRF (e.g., two-gamma function) model that was used in the present study is suitable for studying fMRI responses in the spinal cord of nonhuman primates. Given the known vascular structure differences between the brain and spinal cord, the observations of similar HRFs of the brain and spinal cord support neural origins of the fMRI signals detected in the spinal cord. 
Based to our own published observations, we do not think that the differential activation patterns we observed in heat versus tactile conditions are driven by the anesthesia effects for at least two reasons. First, anesthesia generally suppresses fMRI signals in a dose-, agent-, and cortical-area-dependent manner (for reviews, see Grandjean et al., 2014; Jonckers et al., 2014). Across cortical areas, anesthesia has a significantly weaker influence in early sensory cortical areas and very likely has even a smaller effect in the downstream spinal cord than higher order cognitive brain regions (for review, see Bonhomme et al., 2011). Second, under light isoflurane anesthesia, we have detected fMRI signal changes in widespread brain regions, including those higher-order regions such as insular, cingulate, and prefrontal cortices (Chen et al., 2012), which indicates that the suppressive effects of anesthesia were minimized in our experimental paradigm. In contrast, we obtained increased functional signal-to-noise ratio in the brain under anesthesia (Chen et al., 2005), likely from reduction in motion noise and physiological noise. The same mechanism may explain the enhanced detection of MRI and fMRI signal changes in the spinal cord (Chen et al., 2012; Wang et al., 2013; Wang et al., 2014; Chen et al., 2015). To summarize, we believe that anesthesia is unlikely a major contributor to the differential tactile versus nociceptive heat activation patterns.

\section{Potential of high-resolution fMRI for studying spinal cord circuitry and function}

We attribute our successful detection and quantification of fMRI responses to stimuli in the spinal cord to several technical improvements applied in the present study. First, with assistance of a customized neck coil and optimized acquisition of highresolution and high-contrast MTC structural MR images, we were able to visualize clearly and separate the butterfly-shaped GM from WM regions. The enhanced GM-WM contrast permitted precise image alignment and, ultimately, a more accurate localization of the painful stimuli-evoked fMRI responses to the more superficial portion of the $\mathrm{DH}$ and the tactile-stimuli-related activity to the deeper part of the $\mathrm{DH}$.

Second, the application of noise reduction postprocessing procedures appeared to be effective for detecting stimulus related fMRI signal changes within a single 300 image volume run. We found that the most effective noise reduction step is the regression of a nuisance parameter derived from the CSF and muscle voxels. The observations of reproducible fMRI activation patterns and robust fMRI signal changes indicate the reliability of the differential activations patterns to heat versus touch.

Finally, the effectiveness of our experimental approaches were demonstrated by our postmortem histology validation (see also Wang et al., 2014). In squirrel monkeys, one segment receives predominantly afferent inputs from one and a half digits (e.g., D2 or D3). Therefore, the afferents of D1-D5 enter the spinal cord at the C5-C7 levels (Florence et al., 1991; Qi et al., 2011). Data acquisition of five 3-mm-thick consecutive axial images allowed for the examination of the spinal somatotopy of the fMRI responses to our stimuli.

In conclusion, the successful implementation of these cuttingedge imaging methods permitted visualization and delineation of differential spinal cord circuitries for nociceptive heat and touch at fine spatial scales that have not been achieved previously.

\section{References}

Abraira VE, Ginty DD (2013) The sensory neurons of touch. Neuron 79: 618-639. CrossRef Medline

Arichi T, Fagiolo G, Varela M, Melendez-Calderon A, Allievi A, Merchant N,
Tusor N, Counsell SJ, Burdet E, Beckmann CF, Edwards AD (2012) Development of BOLD signal hemodynamic responses in the human brain. Neuroimage 63:663-673. CrossRef Medline

Barnes CD, Schadt JC (1979) Release of function in the spinal cord. Prog Neurobiol 12:1-13. CrossRef Medline

Barry RL, Smith SA, Dula AN, Gore JC (2014) Resting state functional connectivity in the human spinal cord. eLife 3:e02812. Medline

Bonhomme V, Boveroux P, Hans P, Brichant JF, Vanhaudenhuyse A, Boly M, Laureys S (2011) Influence of anesthesia on cerebral blood flow, cerebral metabolic rate, and brain functional connectivity. Curr Opin Anaesthesiol 24:474-479. CrossRef Medline

Brieu N, Beaumont E, Dubeau S, Cohen-Adad J, Lesage F (2010) Characterization of the hemodynamic response in the rat lumbar spinal cord using intrinsic optical imaging and laser speckle. J Neurosci Methods 191:151-157. CrossRef Medline

Brooks JC, Kong Y, Lee MC, Warnaby CE, Wanigasekera V, Jenkinson M, Tracey I (2012) Stimulus site and modality dependence of functional activity within the human spinal cord. J Neurosci 32:6231-6239. CrossRef Medline

Cahill CM, Stroman PW (2011) Mapping of neural activity produced by thermal pain in the healthy human spinal cord and brain stem: a functional magnetic resonance imaging study. Magn Reson Imaging 29:342352. CrossRef Medline

Chambers WW, Liu CN, McCouch GP (1970) Cutaneous reflexes and pathways affecting them in the monkey, Macaca mulatta. Exp Neurol 28:243256. CrossRef Medline

Chen HS, Chen J, Sun YY (2000) Contralateral heat hyperalgesia induced by unilaterally intraplantar bee venom injection is produced by central changes: a behavioral study in the conscious rat. Neurosci Lett 284:45-48. CrossRef Medline

Chen LM, Friedman RM, Roe AW (2005) Optical imaging of SI topography in anesthetized and awake squirrel monkeys. J Neurosci 25:7648-7659. CrossRef Medline

Chen LM, Turner GH, Friedman RM, Zhang N, Gore JC, Roe AW, Avison M) (2007) High-resolution maps of real and illusory tactile activation in primary somatosensory cortex in individual monkeys with functional Magn Reson Imaging and optical imaging. J Neurosci 27:9181-9191. CrossRef Medline

Chen LM, Dillenburger BC, Wang F, Tang CH (2012) Differential fMRI activation to noxious heat and tactile stimuli in parasylvian areas of new world monkeys. Pain 153:158-169. CrossRef Medline

Chen LM, Mishra A, Yang PF, Wang F, Gore JC (2015) Injury alters intrinsic functional connectivity within the primate spinal cord. Proc Natl Acad Sci U S A 112:5991-5996. CrossRef Medline

Cook AJ, Woolf CJ, Wall PD, McMahon SB (1987) Dynamic receptive field plasticity in rat spinal cord dorsal horn following C-primary afferent input. Nature 325:151-153. CrossRef Medline

Cook AW, Nathan PW, Smith MC (1984) Sensory consequences of commissural myelotomy: a challenge to traditional anatomical concepts. Brain 107:547-568. CrossRef Medline

Davidoff RA, Hackman JC (1991) Aspects of spinal cord structure and reflex function. Neurol Clin 9:533-550. Medline

Dobek CE, Beynon ME, Bosma RL, Stroman PW (2014) Music modulation of pain perception and pain-related activity in the brain, brain stem, and spinal cord: a functional magnetic resonance imaging study. J Pain 15: 1057-1068. CrossRef Medline

Eippert F, Finsterbusch J, Bingel U, Büchel C (2009) Direct evidence for spinal cord involvement in placebo analgesia. Science 326:404. CrossRef Medline

Florence SL, Wall JT, Kaas JH (1991) Central projections from the skin of the hand in squirrel monkeys. J Comp Neurol 311:563-578. CrossRef Medline

Fujiyoshi K, Yamada M, Nakamura M, Yamane J, Katoh H, Kitamura K, Kawai K, Okada S, Momoshima S, Toyama Y, Okano H (2007) In vivo tracing of neural tracts in the intact and injured spinal cord of marmosets by diffusion tensor tractography. J Neurosci 27:11991-11998. CrossRef Medline

Furue H, Katafuchi T, Yoshimura M (2004) Sensory processing and functional reorganization of sensory transmission under pathological conditions in the spinal dorsal horn. Neurosci Res 48:361-368. CrossRef Medline 
Geuter S, Büchel C (2013) Facilitation of pain in the human spinal cord by nocebo treatment. J Neurosci 33:13784-13790. CrossRef Medline

Ghazni NF, Cahill CM, Stroman PW (2010) Tactile sensory and pain networks in the human spinal cord and brain stem mapped by means of functional MR imaging. Am J Neuroradiol 31:661-667. CrossRef Medline

Glover GH, Li TQ, Ress D (2000) Image-based method for retrospective correction of physiological motion effects in fMRI: RETROICOR. Magn Reson Med 44:162-167. Medline

Grandjean J, Schroeter A, Batata I, Rudin M (2014) Optimization of anesthesia protocol for resting-state fMRI in mice based on differential effects of anesthetics on functional connectivity patterns. Neuroimage 102:838847. CrossRef Medline

Huang D, Yu B (2010) The mirror-image pain: an unclered phenomenon and its possible mechanism. Neurosci Biobehav Rev 34:528-532. CrossRef Medline

Jonckers E, Delgado y Palacios R, Shah D, Guglielmetti C, Verhoye M, Van der Linden A (2014) Different anesthesia regimes modulate the functional connectivity outcome in mice. Magn Reson Med 72:1103-1112. CrossRef Medline

Kim SH, Chung JM (1992) An experimental model for peripheral neuropathy produced by segmental spinal nerve ligation in the rat. Pain 50:355363. CrossRef Medline

Koltzenburg M, Wall PD, McMahon SB (1999) Does the right side know what the left is doing? Trends Neurosci 22:122-127. CrossRef Medline

Kong Y, Eippert F, Beckmann CF, Andersson J, Finsterbusch J, Büchel C, Tracey I, Brooks JC (2014) Intrinsically organized resting state networks in the human spinal cord. Proc Natl Acad Sci U S A 111:18067-18072. CrossRef Medline

Logothetis NK (2002) The neural basis of the blood-oxygen-leveldependent functional magnetic resonance imaging signal. Philos Trans $\mathrm{R}$ Soc Lond B Biol Sci 357:1003-1037. CrossRef Medline

Lundell H, Nielsen JB, Ptito M, Dyrby TB (2011) Distribution of collateral fibers in the monkey cervical spinal cord detected with diffusion-weighted magnetic resonance imaging. Neuroimage 56:923-929. CrossRef Medline

Marxen M, Cassidy RJ, Dawson TL, Ross B, Graham SJ (2012) Transient and sustained components of the sensorimotor BOLD response in fMRI. Magn Reson Imaging 30:837-847. CrossRef Medline

Nash P, Wiley K, Brown J, Shinaman R, Ludlow D, Sawyer AM, Glover G, Mackey S (2013) Functional magnetic resonance imaging identifies somatotopic organization of nociception in the human spinal cord. Pain 154:776-781. CrossRef Medline

Petkó M, Antal M (2012) Propriospinal pathways in the dorsal horn (laminae I-IV) of the rat lumbar spinal cord. Brain Res Bull 89:41-49. CrossRef Medline

Qi HX, Chen LM, Kaas JH (2011) Reorganization of somatosensory cortical areas $3 \mathrm{~b}$ and 1 after unilateral section of dorsal columns of the spinal cord in squirrel monkeys. J Neurosci 31:13662-13675. CrossRef Medline

Sprenger C, Eippert F, Finsterbusch J, Bingel U, Rose M, Büchel C (2012)
Attention modulates spinal cord responses to pain. Curr Biol 22:10191022. CrossRef Medline

Stanfa LC, Dickenson AH (2004) In vivo electrophysiology of dorsal-horn neurons. Methods Mol Med 99:139-153. Medline

Stroman PW, Wheeler-Kingshott C, Bacon M, Schwab JM, Bosma R, Brooks J, Cadotte D, Carlstedt T, Ciccarelli O, Cohen-Adad J, Curt A, Evangelou N, Fehlings MG, Filippi M, Kelley BJ, Kollias S, Mackay A, Porro CA, Smith S, Strittmatter SM, et al. (2014) The current state-of-the-art of spinal cord imaging: methods. Neuroimage 84:1070-1081. CrossRef Medline

Stroman PW, Bosma RL, Tsyben A (2012) Somatotopic arrangement of thermal sensory regions in the healthy human spinal cord determined by means of spinal cord functional MRI. Magn Reson Med 68:923-931. CrossRef Medline

Summers PE, Ferraro D, Duzzi D, Lui F, Iannetti GD, Porro CA (2010) A quantitative comparison of BOLD fMRI responses to noxious and innocuous stimuli in the human spinal cord. Neuroimage 50:1408-1415. CrossRef Medline

Summers PE, Porro CA, Giove F (2013) Somatotopy of nociceptive responses in the human spinal cord. Pain 154:2572-2573. Medline

Vanduffel W, Zhu Q, Orban GA (2014) Monkey cortex through fMRI glasses. Neuron 83:533-550. CrossRef Medline

Wang F, Qi HX, Zu Z, Mishra A, Tang C, Gore JC, Chen LM (2014) Multiparametric MRI reveals dynamic changes in molecular signatures of injured spinal cord in monkeys. Magn Reson Med. In press.

Wang F, Li K, Mishra A, Gochberg D, Min Chen L, Gore JC (2015) Longitudinal assessment of spinal cord injuries in nonhuman primates with quantitative magnetization transfer. Magn Reson Med. In press.

Wang Z, Chen LM, Négyessy L, Friedman RM, Mishra A, Gore JC, Roe AW (2013) The relationship of anatomical and functional connectivity to resting-state connectivity in primate somatosensory cortex. Neuron 78 : 1116-1126. CrossRef Medline

Wheeler-Kingshott CA, Stroman PW, Schwab JM, Bacon M, Bosma R, Brooks J, Cadotte DW, Carlstedt T, Ciccarelli O, Cohen-Adad J, Curt A, Evangelou N, Fehlings MG, Filippi M, Kelley BJ, Kollias S, Mackay A, Porro CA, Smith S, Strittmatter SM, et al. (2014) The current state-ofthe-art of spinal cord imaging: applications. Neuroimage 84:1082-1093. CrossRef Medline

Willis WDJ, Coggeshall RE (2004a) Structure of the dorsal horn. New York: Kluwer Academic/Plenum.

Willis WDJ, Coggeshall RE (2004b) Sensory mechanisms of the spinal cord: ascending sensory tracts and their descending control, Ed 3. New York: Kluwer Academic/Plenum.

Woolf CJ (2011) Central sensitization: implications for the diagnosis and treatment of pain. Pain 152:S2-15. CrossRef Medline

Woolf CJ, Salter MW (2000) Neuronal plasticity: increasing the gain in pain. Science 288:1765-1769. CrossRef Medline

Woolrich MW, Jenkinson M, Brady JM, Smith SM (2004) Fully Bayesian spatio-temporal modeling of FMRI data. IEEE Trans Med Imaging 23: 213-231. CrossRef Medline 